\title{
Fontes e Níveis de Energia Digestível em Rações para Suínos Machos Inteiros dos 60 aos $100 \mathrm{~kg}^{1}$
}

\author{
Alessandra Gimenez Mascarenhas ${ }^{2}$, Juarez Lopes Donzele ${ }^{3}$, Rita Flávia Miranda de Oliveira ${ }^{3}$, \\ Aloízio Soares Ferreira ${ }^{3}$, Rogério dos Santos Lopes ${ }^{4}$, Sandra Lúcia Tavares ${ }^{5}$
}

RESUMO - Visando avaliar o efeito de duas fontes lipídicas (óleo de soja e gordura de coco) e de quatro níveis de energia digestível $(3350,3450,3550$ e $3650 \mathrm{kcal} / \mathrm{kg}$ de ração) sobre o desempenho de suínos machos inteiros, dos 60 aos $100 \mathrm{~kg}$, foram utilizados oitenta animais, distribuídos num arranjo fatorial 2 x 4 (fontes x níveis de energia), em delineamento de blocos ao acaso, com cinco repetições de dois animais por baia. As rações experimentais, formuladas à base de milho, farelo de soja e suplemento mineral-vitamínico; foram fornecidas à vontade até o fim do período experimental, quando os animais atingiram o peso médio de 100,40 $\pm 5,67 \mathrm{~kg}$. Não houve efeito do nível de energia digestível (ED) sobre o consumo de ração diário e ganho de peso diário; no entanto, estes parâmetros foram influenciados pela fonte de energia, sendo os melhores resultados obtidos com a utilização da gordura de coco. A conversão alimentar foi influenciada de forma quadrática pelos níveis de ED, quando se utilizou a gordura de coco. Não se observou efeito do óleo de soja sobre a conversão alimentar. A eficiência de utilização da energia para ganho melhorou de forma quadrática, com a utilização da gordura de coco e piorou linearmente com o uso do óleo de soja nas rações. O consumo de energia digestível não foi influenciado pela variação dos níveis de ED e o consumo de lisina diário também não foi influenciado pelos níveis de ED, embora tenha sido maior quando a gordura de coco foi utilizada como fonte lipídica. Rações contendo gordura de coco como fonte lipídica proporcionaram melhor resultado de ganho de peso. A melhor resposta de conversão alimentar dos animais que receberam as rações contendo gordura de coco foi estimada no nível de 3583 kcal.

Palavras-chave: gordura de coco, nutrição, óleo de soja, suínos em terminação

\section{Lipidic Sources and Digestible Energy Levels in Rations for 60 to $100 \mathrm{~kg}$ Boars}

ABSTRACT - To evaluate the effects from two lipid sources (soybean oil and coconut oil) and of four energy levels (3350, 3450 , 3550 and $3650 \mathrm{kcal} / \mathrm{kg}$ ration) on performance from 60 to $100 \mathrm{~kg}$ boars, eighty animals were used. The experimental design of randomized blocks with a factorial arrangement of $2 \times 4$ (sources x energy levels), with five replications of two animals per box, was used. Experimental diets formulated on the basis of maize, soybean meal and vitaminic and mineral supplement were feed ad libitum until the end of the experimental period when animals reached $100.40 \pm 5.67 \mathrm{~kg}$ average weight. There was no effect of the digestible energy (DE) level on the daily feed intake neither on the daily weight gain; however, these parameters were influenced by the energy source and the best results obtained with the use of the coconut oil. The feed:gain ratio was influenced in a quadratic way by the DE levels, when using the coconut oil. No effects of the soybean oil were observed on feed:gain ratio. The efficiency of the energy use for weight gain was improved in a quadratic way when using the coconut oil and linearly worsened when using the soybean oil in the diets. The digestible energy intake was not influenced by changing in the DE levels. The daily intake of lysine was not influenced by the DE levels, although it was higher when the coconut oil was used as lipidic source. Diets with coconut oil as lipidic source showed the best results of weight gain. The best value of feed:gain ratio of the animals that received diets with coconut oil was estimated in level of $3583 \mathrm{kcal}$.

Key Words: coconut oil, nutrition, soybean oil, finishing pigs

\section{Introdução}

A alimentação representa a maior parte do total do custo de produção de suínos. Desta forma, a necessidade de se otimizar a eficiência alimentar é uma realidade e será alcançada à medida que a disponibilidade de nutrientes nos alimentos e as exigências dos suínos, nos diferentes estádios de desen- volvimento, para cada nutriente, forem conhecidas.

Uma vez que o sexo dos animais tem sido um dos principais fatores que influenciam o aproveitamento da energia para retenção de proteína e de gordura na carcaça, bem como a exigência energética para mantença e que suínos machos inteiros têm produzido carcaças mais magras e com maior concentração de proteína do que os machos castrados e as fêmeas

\footnotetext{
${ }_{1}$ Parte do Trabalho de tese de Doutorado do primeiro autor- Projeto financiado pela FAPEMIG.

2 Professora do Departamento de Zootecnia da União Pioneira de Integração Social - UPIS. E.mail: alessandr02311@upis.br

${ }^{3}$ Professor do Departamento de Zootecnia da Universidade Federal de Viçosa - UFV.

4 Doutor/Universidade Federal de Viçosa - UFV.

5 Professora da Universidade Estadual do Sudoeste da Bahia - UESB.
} 
(Holmes et al., 1980), a sua exigência de energia digestível para mantença deve ser maior.

A maior capacidade de retenção de nitrogênio e a produção de tecido magro pelos suínos machos inteiros têm favorecido maior produção de calor corporal em animais deste sexo (Knudson et al., 1986), uma vez que a síntese de proteína é aparentemente menos eficiente, em termos energéticos, que a síntese de gordura, o que pode, provavelmente, explicar $o$ aumento na exigência energética destes animais.

Considerando-se que os suínos consomem os alimentos para atender prioritariamente sua necessidade energética e que a quantidade e a qualidade da energia consumida influenciam a deposição de gordura e proteína na carcaça de suínos de diferentes pesos, torna-se de fundamental importância o conhecimento da relação entre o consumo de energia e o consumo de proteína na partição dos nutrientes, para deposição de proteína e lipídios (Machado \& Penz Jr., 1992; Carnino, 1994) e para a elaboração de estratégias de alimentação para suínos de diferentes sexos.

No entanto, deve-se considerar que os nutrientes diferem na forma de produzir calor como incremento calórico, o que interfere na quantidade de energia disponível para o animal. Tem-se verificado que existe considerável variação nos valores da energia dietética entre as diferentes gorduras e óleos em razão de diferenças na estrutura química, na taxa de inclusão na dieta ou na idade do animal (Wiseman, 1991).

O perfil de ácidos graxos na dieta pode ser um dos principais fatores que influenciam o desempenho dos suínos. O óleo de soja contém predominantemente ácidos graxos insaturados de cadeia longa, com uma relação insaturados/saturados (I/S) de 5,42; na gordura de coco predominam ácidos graxos saturados de cadeia média com uma relação (I/S) de 0,15 (Li et al., 1990).

A alta proporção de ácidos graxos de cadeia média $(>80 \%$ ) pode tornar a gordura de coco uma fonte de lipídio mais efetiva para suínos que as outras fontes energéticas, pois tem-se constatado que ácidos graxos de cadeia média são absorvidos mais rapidamente no lúmen intestinal e mais rapidamente metabolizados que os ácidos graxos de cadeia longa, podendo, então, serem utilizados mais eficientemente que as gorduras compostas de ácidos graxos de cadeia longa (Cera et al., 1989a,b; Wieland et al., 1993).

Assim, verifica-se ser necessário estudar fontes lipídicas(óleo de soja egordura de coco) eníveis de energia digestível (3350,3450,3550 e 3650 kcal/kg de ração) para suínos machos inteiros a partir dos $60 \mathrm{~kg}$ de peso.

\section{Material e Métodos}

O experimento foi conduzido no setor de suinocultura do Departamento de Zootecnia da UFV, no período de setembro a dezembro de 1998 .

Foram utilizados 80 suínos machos inteiros, com peso inicial médio de $61,25 \pm 2,95 \mathrm{~kg}$, distribuídos num arranjo fatorial $2 \times 4$, duas fontes de lipídios (óleo de soja e gordura de coco) e quatro níveis de energia digestível $(3350,3450,3550$ e $3650 \mathrm{kcal} / \mathrm{kg}$ de ração), em delineamento experimental de blocos ao acaso, com cinco repetições e dois animais por repetição.

Foram adotados como critérios para a distribuição dos animais nos blocos, o peso inicial e o parentesco.

Os animais foram alojados em baias providas de comedouros semi-automáticos e bebedouros tipo chupeta, localizadas em um galpão de alvenaria com piso de concreto e coberto com telhas de barro. A temperatura interna do galpão foi registrada diariamente, às 8:00 e às 15:00 horas, por meio de termômetros de máxima e mínima e de bulbo seco e bulbo úmido instalados no meio do galpão, a uma altura correspondente à dos animais.

As rações experimentais foram formuladas para serem isoprotéicas e isolisínicas utilizando-se milho, farelo de soja e suplemento vitamínico-mineral. $\mathrm{Na}$ formulação das rações, levou-se em conta as exigências de suínos em terminação, que constam em ROSTAGNO et al., (1992), e o ajuste dos níveis de energia digestível (ED) foi feito alterando-se a proporção do inerte (areia lavada), do óleo de soja ou da gordura de coco das rações. A composição percentual das rações experimentais bem como as suas composições calculadas encontram-se apresentadas na Tabela 1.

Os animais tiveram livre acesso às rações e à água.

As variáveis de desempenho (ganho de peso, consumo de ração e conversão alimentar) e a eficiência de utilização de ED para ganho foram determinadas mediante pesagens semanais dos animais, das rações fornecidas e das respectivas sobras durante o período experimental, que foi encerrado quando os animais alcançaram o peso médio de $100,40 \pm 5,67 \mathrm{~kg}$.

Os dados foram analisados por meio de análise de variância e regressão. Para o fator qualitativo (fonte), as médias foram comparadas utilizando-se o teste de F, adotando o nível de $10 \%$ de probabilidade. Para o fator quantitativo (níveis), os modelos foram esco- 
Tabela 1 - Composição percentual das rações experimentais

Table 1 - Centesimal composition of the experimental diets

\begin{tabular}{|c|c|c|c|c|c|c|c|c|}
\hline \multirow{3}{*}{$\begin{array}{l}\text { Ingrediente }(\%) \\
\text { Ingredient }\end{array}$} & \multicolumn{8}{|c|}{$\begin{array}{l}\text { Dieta experimental } \\
\text { Experimental diet }\end{array}$} \\
\hline & \multicolumn{4}{|c|}{$\begin{array}{c}\text { Gordura de coco } \\
\text { Coconut Fat }\end{array}$} & \multicolumn{4}{|c|}{$\begin{array}{c}\text { Óleo de Soja } \\
\text { Soybean Oil }\end{array}$} \\
\hline & 3350 & 3450 & 3550 & 3650 & 3350 & 3450 & 3550 & 3650 \\
\hline $\begin{array}{l}\text { Milho } \\
\text { Corn }\end{array}$ & 66,53 & 66,53 & 66,53 & 66,53 & 66,53 & 66,53 & 66,53 & 66,53 \\
\hline $\begin{array}{l}\text { Farelo de soja } \\
\text { Soybean meal }\end{array}$ & 24,60 & 24,60 & 24,60 & 24,60 & 24,60 & 24,60 & 24,60 & 24,60 \\
\hline $\begin{array}{l}\text { Gordura de coco } \\
\text { Coconutfat }\end{array}$ & 2,24 & 3,38 & 4,53 & 5,67 & - & - & - & - \\
\hline $\begin{array}{l}\text { Óleo de soja }{ }^{1} \\
\text { Soybean oil }\end{array}$ & - & - & - & - & 2,45 & 3,71 & 4,97 & 6,22 \\
\hline $\begin{array}{l}\text { Areia lavada } \\
\text { Washed sand }\end{array}$ & 4,07 & 2,93 & 1,78 & 0,64 & 3,86 & 2,60 & 1,34 & 0,09 \\
\hline $\begin{array}{l}\text { Calcário } \\
\text { Limestone }\end{array}$ & 1,00 & 1,00 & 1,00 & 1,00 & 1,00 & 1,00 & 1,00 & 1,00 \\
\hline $\begin{array}{l}\text { Fosfato bicálcico } \\
\text { Dicalcium phosphate }\end{array}$ & 1,10 & 1,10 & 1,10 & 1,10 & 1,10 & 1,10 & 1,10 & 1,10 \\
\hline $\begin{array}{l}\text { Sal } \\
\text { Salt }\end{array}$ & 0,30 & 0,30 & 0,30 & 0,30 & 0,30 & 0,30 & 0,30 & 0,30 \\
\hline $\begin{array}{l}\text { Mistura mineral } \\
\text { Mineral mix } \\
\text { Mistura vitamínica } \\
\text { Mis }\end{array}$ & 0,05 & 0,05 & 0,05 & 0,05 & 0,05 & 0,05 & 0,05 & 0,05 \\
\hline $\begin{array}{l}\text { Vitaminic Mix } \\
\text { BHT }\end{array}$ & $\begin{array}{l}0,10 \\
0,01\end{array}$ & $\begin{array}{l}0,10 \\
0,01\end{array}$ & $\begin{array}{l}0,10 \\
0,01\end{array}$ & $\begin{array}{l}0,10 \\
0,01\end{array}$ & $\begin{array}{l}0,10 \\
0,01\end{array}$ & $\begin{array}{l}0,10 \\
0,01\end{array}$ & $\begin{array}{l}0,10 \\
0,01\end{array}$ & $\begin{array}{l}0,10 \\
0,01\end{array}$ \\
\hline$B H T$ & & & & & & & & \\
\hline $\begin{array}{l}\text { Total } \\
\text { Composição Calculada } 4 \\
\text { Calculated composition } \\
\text { Energia digestível }\end{array}$ & 100 & 100 & 100 & 100 & 100 & 100 & 100 & 100 \\
\hline $\begin{array}{l}\text { Digestible energy }(\mathrm{kcal} / \mathrm{kg}) \\
\text { Proteína bruta }(\%)\end{array}$ & $\begin{array}{l}3350 \\
16,98\end{array}$ & $\begin{array}{l}3450 \\
16,98\end{array}$ & $\begin{array}{l}3550 \\
16,98\end{array}$ & $\begin{array}{l}3650 \\
16,98\end{array}$ & $\begin{array}{l}3350 \\
16,98\end{array}$ & $\begin{array}{l}3450 \\
16,98\end{array}$ & $\begin{array}{l}3550 \\
16,98\end{array}$ & $\begin{array}{l}3650 \\
16,98\end{array}$ \\
\hline $\begin{array}{l}\text { Crude protein } \\
\text { Lisina }(\%) \\
\text { Lysine }\end{array}$ & 0,86 & 0,86 & 0,86 & 0,86 & 0,86 & 0,86 & 0,86 & 0,86 \\
\hline $\begin{array}{l}\text { Cálcio }(\%) \\
\text { Calcium }\end{array}$ & 0,74 & 0,74 & 0,74 & 0,74 & 0,74 & 0,74 & 0,74 & 0,74 \\
\hline $\begin{array}{l}\text { Fósforo disponível } \\
\text { Available } P(\%)\end{array}$ & 0,31 & 0,31 & 0,31 & 0,31 & 0,31 & 0,31 & 0,31 & 0,31 \\
\hline
\end{tabular}

1 Valores de ED segundo Brustolini et al. (2001): gordura de coco: $8745,18 \mathrm{kcal} / \mathrm{kg}$ e óleo de soja: $7992,88 \mathrm{kcal} / \mathrm{kg}$. (DE values according to Brustolini et al. (2001): coconut fat $-8745.18 \mathrm{kcal} / \mathrm{kg}$ and soybean oil $-7992.88 \mathrm{kcal} / \mathrm{kg}$ ).

2 Mistura mineral (Mineral premix): Mn:30.000mg; Zn: 140.000 mg; Cu: 16.000 mg; Fe: 90.000 mg; Co: 200 mg; I: 850 mg; veículo (vehicle) qsp.1000 g.

${ }^{3}$ Mistura vitamínica (vitamin premix): Vit A: $6.000 .000 \mathrm{UI}:$ Vit $\mathrm{D}_{3} 1.500 .000 \mathrm{Ul}$; Vit E: $15.000 \mathrm{Ul}$; Vit $\mathrm{K}_{3}: 1500 \mathrm{mg}$; Vit $\mathrm{B}_{1}: 1350 \mathrm{mg}$; Vit $\mathrm{B}_{2}: 4000 \mathrm{mg}$; Vit $\mathrm{B}_{6}: 2000 \mathrm{mg}$; Vit $\mathrm{B}_{12}: 20.000 \mathrm{mg}$; Ácido pantotênico (pantotenic acid): $9350 \mathrm{mg}$; Biotina (biotin): $80 \mathrm{mg}$; Ácido fólico (folic acid): $600 \mathrm{mg}$ Se: $300 \mathrm{mg}$; veículo (vehicle) qsp:1000g.

${ }^{4}$ Composição calculada com base nos valores contidos em Rostagno et al. (1992) (Calculated composition basis of Rostagno et al. [1992]).

lhidos com base na significância dos coeficientes de regressão, no coeficiente de determinação e no fenômeno biológico (em estudo). Utilizou-se para a realização dessas análises o programa ANOVAG, contido no Sistema para Análises Estatísticas e Genéticas - SAEG (UFV, 1997).

\section{Resultados e Discussão}

Os resultados de consumo de ração diário (CRD), ganho de peso diário (GPD), conversão alimentar (CA), eficiência de utilização da energia digestível para ganho (EG), consumo de ED (CED) e consumo 
de lisina diário (CLD) estão apresentados na Tabela 2. Não houve efeito da interação $(P>0,10)$ entre as fontes e os níveis de ED para CRD e GPD.

Os níveis de ED das rações não influenciaram o CRD dos animais. Estes resultados foram similares aos obtidos por Godoy et al. (1996), que não verificaram variação no CRD dos suínos em crescimento em razão do aumento do nível de ED das rações, de 3150 para $3550 \mathrm{kcal}$, e aos resultados obtidos por Jones (1997) e Silva et al. (1998), que trabalharam com suínos em terminação para avaliar níveis de ED variando de 3150 a $3700 \mathrm{kcal} / \mathrm{kg}$ e de 3200 a $3700 \mathrm{kcal} / \mathrm{kg}$ de ração, respectivamente.

Embora o CRD dos animais não tenha variado em razão do aumento do nível de energia da ração, constatou-se que o consumo de ração diário daqueles que receberam as rações contendo gordura de coco como fonte de energia foi $4,3 \%$ maior $(\mathrm{P}<0,08)$ que o daqueles que receberam rações contendo óleo de soja.

Não se observou efeito $(\mathrm{P}>0,10)$ dos níveis de ED das rações sobre o GPD. Resultados similares foram obtidos por Barbosa et al. (1979) e Jones (1997) com suínos machos inteiros, dos 60 aos $100 \mathrm{~kg}$, avaliando níveis de ED variando de 3150 a $3700 \mathrm{kcal} / \mathrm{kg}$ de ração. Por outro lado, Quiniou et al. (1996 a,b) e Silva et al. (1998) observaram um aumento linear no GPD em razão do aumento do nível de energia das rações fornecidas a suínos machos inteiros, na fase de terminação. A melhora no GPD, observada pelos autores acima citados, foi associada a um aumento no CED dos animais entre os tratamentos; o que não foi verificado neste trabalho. Além deste aspecto, o nível de proteína das rações experimentais e o genótipo dos animais utilizados são fatores que também podem ter contribuído para as variações nos resultados observados entre os trabalhos. Segundo Bikker (1994), o genótipo dos suínos influencia a relação entre a ingestão de energia e a deposição de proteína no corpo e, conseqüentemente, o ganho de peso.

O fato de o GPD não ter se alterado entre os níveis de ED avaliados estaria indicando que pelo nível de lisina utilizado, correspondente à relação de $0,25 \mathrm{~g}$ de lisina/1000 kcal no nível mais baixo de ED, a energia não foi limitante para o ganho de peso, sendo suficiente para atender as exigências dos animais.

A fonte de energia influenciou $(\mathrm{P}<0,09)$ o GPD, que foi 5,3\% maior nos animais consumindo as rações contendo gordura de coco, em relação àqueles consumindo rações contendo óleo de soja. Essa melhora

Tabela 2 - Consumo de ração diário (CRD), ganho de peso diário (GPD), conversão alimentar (CA), eficiência de utilização da energia para ganho (EG), consumo de energia digestível (CED) e consumo de lisina diário (CLD) de suínos machos inteiros dos 60 aos $100 \mathrm{~kg}$ de peso, recebendo diferentes fontes e níveis de energia digestível

Table 2 - Daily feed intake (DFI), daily weight gain (DWG), feed:gain (F:G), efficiency of utilization the DE for gain (EG), digestible energy intake (DEI) and daily lysine intake (DLI) of boars from 60 to $100 \mathrm{~kg}$ feeding different sources and digestible energy levels

\begin{tabular}{|c|c|c|c|c|c|c|c|c|c|c|c|c|}
\hline \multirow[t]{2}{*}{$\begin{array}{l}\text { Parâmetro } \\
\text { Parameter }\end{array}$} & \multicolumn{4}{|c|}{$\begin{array}{l}\text { Gordura de coco } \\
\text { Coconut oil }\end{array}$} & \multirow[b]{2}{*}{$\begin{array}{l}\text { Média } \\
\text { Average }\end{array}$} & \multirow[b]{2}{*}{$\begin{array}{l}\mathrm{CV} \\
(\%)\end{array}$} & \multicolumn{4}{|c|}{$\begin{array}{l}\text { Óleo de soja } \\
\text { Soybean oil }\end{array}$} & \multirow[b]{2}{*}{$\begin{array}{l}\text { Média } \\
\text { Average }\end{array}$} & \multirow[b]{2}{*}{$\begin{array}{l}\text { CV } \\
(\%)\end{array}$} \\
\hline & 3350 & 3450 & 3550 & 3650 & & & 3350 & 3450 & 3550 & 3650 & & \\
\hline $\begin{array}{l}\overline{C R D}(\mathrm{~g} / \mathrm{dia})^{1} \\
D F I\end{array}$ & 2739 & 2762 & 2626 & 2622 & $2687^{\mathrm{A}}$ & 5,3 & 2659 & 2616 & 2584 & 2443 & $2576^{\mathrm{B}}$ & 9,5 \\
\hline $\begin{array}{l}\text { GPD }(\mathrm{g} / \mathrm{dia})^{1} \\
D W G\end{array}$ & 1165 & 1228 & 1180 & 1173 & $1187^{\mathrm{A}}$ & 5,2 & 1190 & 1137 & 1133 & 1046 & $1127^{\mathrm{B}}$ & 13,7 \\
\hline $\begin{array}{l}\mathrm{CA}(\mathrm{g} / \mathrm{g})^{2} \\
F: G\end{array}$ & $2,35^{\mathrm{Q}}$ & 2,25 & 2,22 & 2,23 & 2,26 & 2,2 & 2,23 & 2,32 & 2,27 & 2,34 & 2,29 & 5,1 \\
\hline $\begin{array}{l}\text { EG }(\mathrm{kcal} / \mathrm{g} \text { de ganho })^{3} \\
\text { CED }(\mathrm{kccl} / \mathrm{dia})^{1}\end{array}$ & $\begin{array}{l}7,87^{Q} \\
9176\end{array}$ & $\begin{array}{l}7,76 \\
9530\end{array}$ & $\begin{array}{l}7,91 \\
9322\end{array}$ & $\begin{array}{l}8,16 \\
9572\end{array}$ & $\begin{array}{c}7,92 \\
9400^{\mathrm{A}}\end{array}$ & $\begin{array}{l}2,2 \\
5,3\end{array}$ & $\begin{array}{l}7,49^{\mathrm{L}} \\
8910\end{array}$ & $\begin{array}{l}8,03 \\
9026\end{array}$ & $\begin{array}{l}8,09 \\
9176\end{array}$ & $\begin{array}{l}8,56 \\
8919\end{array}$ & $\begin{array}{c}8,04 \\
9017^{\mathrm{B}}\end{array}$ & $\begin{array}{l}5,1 \\
9,5\end{array}$ \\
\hline$D E I$ & & & & & & & & & & & & \\
\hline $\begin{array}{l}\operatorname{CLD}(\mathrm{g} / \mathrm{dia})^{1} \\
D L I\end{array}$ & 23,5 & 23,7 & 22,6 & 22,5 & $23,1^{\mathrm{A}}$ & 5,3 & 22,9 & 22,5 & 22,2 & 21,0 & $22,1^{\mathrm{B}}$ & 9,6 \\
\hline
\end{tabular}

\footnotetext{
${ }_{1}^{1}$ Houve efeito de fonte. Médias seguidas de letras diferentes na mesma linha diferem entre si pelo teste de $F(P<0,10)$

1 There was effect of source. Means followed by different letters in the same row, differ per by $F$ test $(P<0.10)$.

2 Houve interação entre fonte $x$ nível de ED $(P<0,09)$; $Q$ Efeito quadrático $(P<0,03)$.

2 There was interaction between source and DE level $(P<0.09)$; Q Quadratic effect $(P<0.03)$.

${ }^{3}$ Houve interação entre fonte $x$ nível de $\operatorname{ED}(P<0,10)$; $Q$ Efeito quadrático $(P<0,04)$; L Efeito linear $(P<0,03)$.

${ }^{3}$ There was interaction between source and $D E$ level $(P<0.10)$; $Q$ Quadratic effect $(P<0.04) .{ }^{L}$ Linear effect $(P<0.03)$.
}

\section{R. Bras. Zootec., v.31, n.3, p.1403-1408, 2002 (suplemento)}


no GPD pode ser justificada pelo maior CRD e, consequentemente, pelo maior consumo de lisina pelos animais que receberam as rações contendo gordura de coco como fonte de energia.

Houve interação $(P<0,09)$ entre as fontes e os níveis de ED para $\mathrm{CA}$, que não variou $(\mathrm{P}>0,10)$ entre os níveis em que se utilizou o óleo de soja $(\hat{Y}=2,29)$ e que reduziu de forma quadrática $(\mathrm{P}<0,03)$ entre os níveis de ED das rações contendo gordura de coco, até o nível estimado de $3583 \mathrm{kcal}$ de $\mathrm{ED} / \mathrm{kg}$ de ração.

A conversão alimentar dos animais em função do nível de ED quando se utilizou a gordura de coco como fonte de energia, está apresentada na Figura 1.

O nível de ED que proporcionou melhores resultados de CA nos animais que receberam ração contendo gordura de coco foi semelhante àquele de $3575 \mathrm{kcal}$ de $\mathrm{ED} / \mathrm{kg}$ de ração encontrado por Silva et al. (1998), em estudo com suínos machos inteiros, na fase de terminação, utilizando óleo de soja nas rações.

Apesar de ter ocorrido interação, constatou-se que as variações dos valores observados de CA, nos diferentes níveis e fontes de ED, foram próximas. Este fato corrobora o relato anterior em que a variação no ganho de peso médio dos animais, recebendo as diferentes fontes de ED, foi devida à variação verificada no consumo.

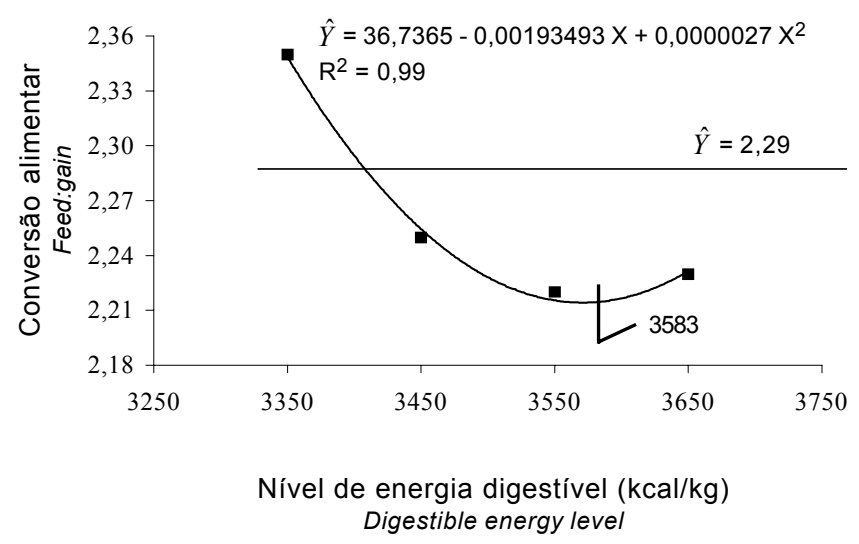

Figura 1 - Estimativa da conversão alimentar de suínos machos inteiros, de 60 a $100 \mathrm{~kg}$, em função do nível de energia digestível, com a utilização de gordura de coco ( $\square$ ) e de óleo de soja (-) como fonte lipídica.

Figure 1 - Feed:gain of the boars from 60 to $100 \mathrm{~kg}$, according to the DE level of diets with coconut oil (ם) and soybean oil (-) as lipidic source.

R. Bras. Zootec., v.31, n.3, p.1403-1408, 2002 (suplemento)
Ocorreu interação $(\mathrm{P}<0,10)$ entre as fontes e os níveis de energia para eficiência de utilização de ED para ganho (EG), que melhorou $(\mathrm{P}<0,04)$ até o nível de $3477 \mathrm{kcal}$ de ED, estimado pela equação $\hat{Y}=115,597-0,0625931 \mathrm{X}+0,0000090 \mathrm{X}^{2}$, quando se utilizou a gordura de coco e piorou $(\mathrm{P}<0,03)$ de forma linear segundo a equação $\hat{Y}=-3,23516+0,0032144 X$, quando o óleo de soja foi a fonte de lipídio utilizada, o que é mostrado na Figura 2.

Com exceção do resultado obtido com o nível de $3450 \mathrm{kcal}$ de $\mathrm{ED} / \mathrm{kg}$ de ração quando se utilizou a gordura de coco, a piora observada na eficiência de utilização da energia para ganho com o aumento no nível de ED estaria de acordo com os dados calculados a partir dos resultados obtidos por Silva et al. (1998).

Não se observou efeito $(\mathrm{P}>0,10)$ dos níveis de ED das rações sobre o CED, no entanto, os animais que receberam as rações contendo gordura de coco apresentaram aumento $(\mathrm{P}<0,08)$ de $4,25 \%$ no CED em relação aos que receberam ração com óleo de soja. Este resultado foi diferente dos encontrados por Godoy et al. (1996) e Silva et al. (1998) que, mesmo não encontrando variação significativa no CRD, observaram que o CED aumentou linearmente com o aumento da densidade energética das rações.

As reduções não-significativas ( $\mathrm{P}>0,10)$, de 4,4 e

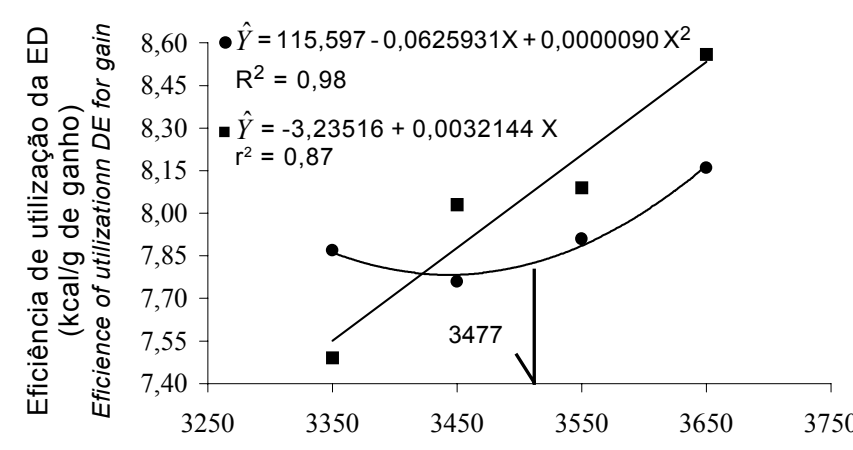

Nível de energia digestível ( $\mathrm{kcal} / \mathrm{kg})$ Digestible energy level

Figura 2 - Eficiência de utilização da energia digestível para ganho de suínos machos inteiros de 60 a $100 \mathrm{~kg}$, em função do nível de energia digestível com a utilização de gordura de coco e do óleo de soja como fontes lipídicas.

Figure 2 - Efficiency of utilization of the DE for gain in the boars from 60 to $100 \mathrm{~kg}$, according to the DE level of diets with coconut oil and soybean oil as lipidic sources. 
8,8\%, observadas no CRD dos animais recebendo rações com gordura de coco e óleo de soja, respectivamente, explicam o fato de os CEDs não terem variado entre os tratamentos, evidenciando que os suínos ajustaram seu consumo em razão do nível energético das rações.

A diferença de CED dos animais entre as fontes explicou o aumento no GP dos animais que receberam ração contendo gordura de coco.

Não se observou variação $(P>0,10)$ no consumo de lisina diário (CLD) entre os níveis de $\mathrm{ED}$, que se manteve acima de $22 \mathrm{~g} /$ dia. No entanto, a fonte de ED influenciou $(\mathrm{P}<0,08)$ o CLD, que foi $4,3 \%$ maior quando se utilizou as rações contendo gordura de coco. A diferença no CLD está diretamente relacionada aos diferentes consumos de ração apresentados pelos animais recebendo rações com as diferentes fontes lipídicas.

\section{Conclusões}

Para suínos machos inteiros, dos 60 aos 100 kg, a utilização de rações contendo gordura de coco como fonte lipídica proporcionou melhor resultado de ganho de peso.

O nível estimado de 3583 kcal de energia digestível resultou em melhor resposta de conversão alimentar dos animais que receberam rações contendo gordura de coco como fonte de lipídios.

O nível de energia digestível das rações contendo óleo de soja não influenciou o desempenho dos animais.

\section{Literatura Citada}

BARBOSA, H.P.; COSTA, V.; FERREIRA, A.S. et al. Efeitos de diferentes níveis de energia, proteína e sistema de alimentação no desempenho e características de carcaça de suínos não castrados no período de crescimento-terminação. Revista Brasileira de Zootecnia, v.8, n.2, p.183-197, 1979.

BIKKER. P. Protein and lipidic accretion in body components of growing pigs: effects of body weight and nutrient intake. [S.1.:Sn] Netherlands, 1994.203p. PhD Thesis, Departament of Animal Nutrition, Wagening Agricultural University, Netherlands, 1994.

BRUSTOLINI, P.C.; SILVA, F.C.O.; DONZELE, J.L. et al. Valores de energia metabolizável de óleo de soja e gordura de coco determinados com suínos em terminação. In: REUNIÃO ANUAL DA SOCIEDADE BRASILEIRA DEZOOTECNIA, 38., 2001, Piracicaba. Anais... Piracicaba: Sociedade Brasileira deZootecnia, 2001. p.775-776.

CARNINO, F. Efeito dos valores fisiológicos e nutricionais e sobre a qualidade de carcaça de suínos. In: SIMPÓSIO LATINO AMERICANO DE NUTRIÇÃO DE SUÍNOS, 1994, São Paulo. Anais... São Paulo: Colégio Brasileiro de Nutrição Animal, 1994. p.133-157.
CERA, K.R.; MAHAN, D.C.; REINHART, G.A. Apparent fat digestibilities and performance responses of postweaning swine fed diets supplemented with coconut oil, corn oil or tallow. Journal of Animal Science, v.67, n.8, p.2040-2047, 1989a.

CERA, K.R.; MAHAN, D.C.; REINHART, G.A. Postweaning swine performance and serum profile responses to supplemental medium-chain free fatty acids and talow. Journal of Animal Science, v.67, n.8, p.2048-2055, 1989 b.

GODOY, M.L.; DONZELE, J.L.; FERREIRA, A.S. Níveis de energia digestível para suínos machos inteiros dos 30 aos $60 \mathrm{~kg}$. Revista Brasileira de Zootecnia, v.25, n.6, p.1139-1149, 1996.

HOLMES, C.W.; CARR, J.R.; PEARSON, G. Some aspects of the energy and nitrogen metabolism of boars, gilts and barrow given diets containing different concentrations of protein. Animal Production, v.31, n.3, p.279-289, 1980.

JONES, R.D. Diets based on early growth may not alter response. Feedstuffs, p.12-13, 1997.

KNUDSON, B.K.; MILLER, G.R.; BERGEN, W.G. et al. Metabolizable and digestible energy of a common let fed to boars and barrows. Journal of Animal Science, v.63(Supl.1), p.113, 1992.

LI, D.F.; THALER, R.C.; NELSSEN, J.L. et al. Effect of fat sources and combinations on starter pig performance, nutrient digestibility and intestinal morphology. Journal of Animal Science, v.68, p.3694-3704, 1990.

MACHADO, C.P.; PENZ JR., A.M. Programa de alimentação de suínos em crescimento-acabamento; múltiplas fases $\mathrm{e}$ criação de animais de diferentes sexos em separado. Porto Alegre: Universidade Federal do Rio Grande do Sul, 1992. p.135-148.

QUINIOU, N.; DOURMAD, J.Y.; NOBLET, J. Effect of energy intake on the performance of different types of pig from 45 to $100 \mathrm{~kg}$ body weight. 1. Protein and lipid deposition. Animal Science, v.63, p.277-288, 1996a.

QUINIOU, N.; DOURMAD, J.Y.; NOBLET, J. Effect of energy intake on the performance of different types of pig from 45 to $100 \mathrm{~kg}$ body weight. 2.Tissue gain. Animal Science, v.63, p.289-296, 1996b.

ROSTAGNO, H.S.; SILVA, D.J.; COSTA, P.M.A. et al. Composição de alimentos e exigências nutricionais de aves e suínos; tabelas brasileiras. Viçosa, MG: Universidade Federal de Viçosa, 1992. 59p.

SILVA, D.J. Análise de alimentos (Métodos químicos e biológicos). Viçosa, MG: Universidade Federal de Viçosa, 1990. 165p.

SILVA, F.C.O.; DONZELE, J.L.; FREITAS, R.T.F. et al. Níveis de energia digestível para suínos machos inteiros e fêmeas dos 60 aos $100 \mathrm{~kg}$. Revista Brasileira de Zootecnia, v.27, n.5, p.959-964, 1998.

UNIVERSIDADE FEDERAL DE VIÇOSA- UFV. SAEG - Sistema de Análises Estatísticas e Genéticas. Versão 7.0. ViçosaMG, 1997. 150p. (manual do usuário).

WIELAND, T.M.; LIN, X.; ODLE, J. Utilization of medium-chain triglycerides by neonatal pigs: Effects of emulsification and dose delivered. Journal of Animal Science, v.71, p.18631868, 1993.

WISEMAN, J. Sources and quality of oils and fats for nonruminants. Digestive physiology in pigs. In: INTERNATIONAL SYMPOSIUM, 5., 1991. Proceedings... 1991. p.147-166. 